\title{
Density functional theory study of mussel adhesive protein (l-dopa \& catechol) cross-linking
}

\begin{abstract}
Marine mussel adhesive proteins (MAPs) irreversibly stick to different wet surfaces. Adhesion involves the cross-linking of the MAPs mediated by transition metal ions that make coordination complexes with Catechol. To better understand this cross-linking, the quantum mechanics/molecular mechanics (QM/MM) method was employed to simulate four different transition metal ions, $\mathrm{Fe}^{2+}, \mathrm{Fe}^{3+}, \mathrm{Cr}^{3+}$ and $\mathrm{Mn}^{3+}$, forming tris complexes with catechol and with 3, 4-dihydroxy phenylalanine (DOPA) modified polyethylene glycol (PEG) polymer. The binding energy of the metal to the ligand is of special interest. This is the molecular origin of the mechanical properties of crosslinked MAPs. To examine the structures and binding energies, density functional theory calculations were performed for different metal ions that make coordination complexes with a catechol through which polymeric ligand similar to MAPs binds to the metal ions. Among the investigated metal ions, $\mathrm{Fe}^{3+}$ gives the strongest cross linking, which is in good agreement with experimental data.
\end{abstract}

Volume I Issue 6 - 2017

\author{
Shabeer Ahmad Mian,' Salem UL Azzam,' \\ Gul Rahman, ${ }^{2}$ Ejaz Ahmed ${ }^{3}$ \\ 'Department of Physics, University of Peshawar, Pakistan \\ ${ }^{2}$ Institute of chemical Sciences, University of Peshawar, Pakistan \\ ${ }^{3}$ Department of physics, Abdul Wali Khan, Pakistan
}

\begin{abstract}
Correspondence: Shabeer Ahmad Mian, Computational Nanomaterials Science Lab, Department of Physics, University of Peshawar, Pakistan, Email shabeerahmad@uop.edu.pk, shabeerahmad@gmail.com
\end{abstract}

Received: October 30, 2017 | Published: November 30, 2017

Keywords: transition metal complex, curing, crosslinking, metal ions, mussels adhesive protein

\begin{abstract}
Abbreviations: DOPA, 3,4-dihydroxy phenylalanine; MAPs, mussel adhesive proteins; QM, quantum mechanics; MM, molecular mechanics; PEG, polyethylene glycol; LAMBA, light activated mussel-based bio adhesive; DFT, density functional theory; EPR, electron paramagnetic resonance; DCTA, double-crosslinked tissue adhesives; UFF, universal force field; ONIOM, own n-layer integrated molecular orbital molecular mechanics
\end{abstract}

\section{Introduction}

Marine mussels adhesive proteins (MAPs) bind to virtually any surface under wet conditions. ${ }^{1,2}$ Over the years, extensive efforts have been made to elucidate this remarkable adhesion property because of the wide potential applications of an adhesive that is capable of sticking to wet surfaces. These applications include bonding of tissue in the wet environment inside the body. In Jo et al. ${ }^{3}$ suggested biomimetic adhesive materials containing cyanoacryl groups for medical application. ${ }^{3}$ Yang and coworkers have introduced an injectable biocompatible biomimetic adhesive for use inside the body. ${ }^{4}$ Mussel adhesive protein inspired injectable citrate-based bioadhesive bone implants have also been developed. ${ }^{5}$ In Jeon et al. ${ }^{6}$ reported a blue light-activated mussel-based bio-adhesive (LAMBA) which is compatible with the human body and binds strongly in wet conditions. ${ }^{6}$ Cross-linking is the keystone to hydrogels. Hydrogel is a three dimensional structure with high water content that is crosslinked together by irreversible chemical bonds. ${ }^{7}$ Conventional wound healing such as sutures or staples leads to scar formation. ${ }^{8}$ Scar formation makes the body part sensitive which restrict body movement and may cause cancer., ${ }^{910}$ Cyanoacrylate and fibrin glue are the commercially available tissue adhesive, besides there advantages these tissue adhesives poses risk to many diseases. ${ }^{11,12}$ Other potential applications include underwater construction. ${ }^{13}$ It is now well known that MAPs contain an unusually high fraction of 3,4-dihydroxyphenylalanine (DOPA). ${ }^{14-16}$ The catechol functionalities (1,2-dihydroxybenzene) of DOPA are believed to anchor MAPs onto surfaces. ${ }^{17,18} \mathrm{~A}$ recent density functional theory (DFT) study has shown that catechol displaces the pre-adsorbed water molecules on a silica surface, and the binding energies and forces involved were calculated. ${ }^{1}$ The versatility of mussel adhesion has been attributed to the fact that catechol has both hydroxyls and a phenylene ring which can establish firm adhesion to both polar and non-polar surfaces. ${ }^{19}$ Messersmith et al. ${ }^{20}$ have developed a tissue adhesive system of four-armed PEG ended with catechol group having strong adhesive strength, low toxicity and excellent wound closure. ${ }^{21-24}$

We note that the adhesion of MAPs requires a relatively slow 1 to 4 hour long ${ }^{14,25}$ curing process in which an extensive cross-linking of these MAPs occurs ${ }^{15,26}$ The catechol, which is the terminal end of the DOPA molecule, has an oxidized form quinone which is believed to be responsible for the cross-linking with transition metals. ${ }^{27}$ However, the exact mechanism of the cross-linking remains elusive, especially at the molecular level. Experimentally, it is found that the transition metal content (e.g. iron, copper and zinc) in the cross linked MAPs reaches up to 100,000 times the levels found naturally in marine water ${ }^{13,15-17}$ Previous studies have speculated that transition metal ions are mainly involved in the protein-protein cross-linking. ${ }^{15}$ Lee and coworkers have studied the effect of $\mathrm{pH}$ on the rate of curing and bioadhesive properties of dopamine functionalized poly (ethylene glycol) hydrogels. ${ }^{20}$

Experimentally, the compression and shear properties of the cross linked MAPs have been estimated by measuring the force required to penetrate a rod through the cross-linked MAPs. ${ }^{15,16}$ These studies showed that the greatest degree of curing was produced by $\mathrm{Fe}^{3+}$ and $\mathrm{Mn}^{3+}$ among the available biological metal ions examined. ${ }^{15,16}$ An electron paramagnetic resonance (EPR) spectroscopic study of the glue produced by mussels revealed a prominent high-spin $\mathrm{Fe}^{3+}$ signal. Mary et al. ${ }^{13}$ also reported that when DOPA-containing protein precursors of mussel glue are cross-linked with $\mathrm{Fe}^{3+}$, high-spin $\mathrm{Fe}^{3+}$ 
and radical signals are observed. ${ }^{17}$ Together, these studies suggest that $\mathrm{Fe}^{3+}$-MAPs cross-linking takes place via formation of tris $\mathrm{Fe}$ (DOPA) ${ }_{3}$ complexes. ${ }^{17,28}$ Gluing mechanism of double-crosslinked tissue adhesives (DCTA) are assigned by the presence of $\mathrm{Fe}^{3+}$ ions and genipin. For fast curing catechol groups are transplanted on gelatin with $\mathrm{Fe}^{3+}$ ions while for long-term curing cross-linker of DCTA (i.e. genipin) forms strong and stable covalent bonds between the gelatin macromers, tissue and adherent. ${ }^{29}$ DCTA has unique advantages over single cross-linking gelatin will adhere to surfaces instantly while genipin will take long time to adhere but the adhesion will be stronger. ${ }^{30}$

In the present work, complexes of transition metal ions $\mathrm{Fe}^{2+}$, $\mathrm{Fe}^{3+}, \mathrm{Cr}^{3+}$, and $\mathrm{Mn}^{3+}$ with DOPA modified polyethylene glycol (PEG) polymers (or with quinone) were studied. The structures and binding strengths of these metal ions with the DOPA modified PEG were calculated using the quantum mechanics/molecular mechanics (QM/ MM) method. The transition metal and surrounding DOPA elements were treated quantum mechanically using the B3LYP method with 6-311G** basis set. The rest of the system is treated with the MM method employing the universal force field (UFF). ${ }^{31}$ The vibrational frequencies of the optimized complex and the binding energies of the metals with the ligands were calculated. The results are discussed and compared with the literature.

\section{Computational methods}

The Gaussian 09 simulation package ${ }^{32}$ was used to calculate the binding energy and Raman spectrum for the cross-linked transition metal complex. $\mathrm{Fe}^{2+}, \mathrm{Fe}^{3+}, \mathrm{Cr}^{3+}$, and $\mathrm{Mn}^{3+}$ ions are cross-linked with DOPA modified polyethylene glycol. Eighteen electron model systems with charges of $-4,-3,-3,-3$ (and spin multiplicity $1,2,3,4$ ) were considered for $\mathrm{Fe}^{2+}, \mathrm{Fe}^{3+}, \mathrm{Cr}^{3+}$, and $\mathrm{Mn}^{3+}$ ions respectively. The hybrid quantum mechanical/molecular mechanics (QM/MM) method was used. ${ }^{33-35}$ We used the ONIOM (our Own N-layer Integrated Molecular Orbital molecular Mechanics) method which can combine a large number of ab initio molecular orbital methods as well as molecular mechanics methods. ${ }^{35-41}$

The ONIOM optimization of the DOPA modified PEG polymer complexes was performed using DFT and the B3LYP formalism, with the 6-311G** basis set for the high layer QM region and UFF for low layer MM region. Our system has 694 atoms in which 37 atoms are in the high layer QM part, and 657 atoms are in the MM region or low layer. The link atom method was utilized. This is the simplest approach because it is not feasible for our system to consider and parameterize frozen orbitals for all possible combination. For the catechol calculation, the $\mathrm{Fe}^{3+}$ metal ion surrounded by three catechols is considered as high layer and the rest of the complex is considered to be the low layer.

In the QM calculation, the resulting dangling bonds need to be saturated, and link atoms are the simplest approach to use. ${ }^{33}$ These are usually hydrogen atoms but can, in principle, be any atom that mimics the part of the system that it substitutes. Link atoms are used in a large proportion of QM/MM implementations as well as in the ONIOM scheme. The main alternative to link atoms is the use of frozen orbitals, which can through parameterization and use of $\mathrm{p}$ and $\mathrm{d}$ orbitals describe a more accurate charge density than link atoms. ${ }^{25,41-43}$ Although few studies that directly compare the link atom method with the frozen orbital method show that both schemes perform well, ${ }^{42,44}$ it appears generally accepted that the latter can provide a better description of the boundary. In our implementation, link atoms were exclusively used to maintain the generality of the ONIOM scheme. The electronegativity can be modified through the use of a shift operator or, in the case of semi empirical QM methods, the parameters involving link atoms can be adjusted. ${ }^{45}$

The electrostatic interaction is evaluated as the interaction of the MM partial charges with partial (point) charges assigned to the atoms in the QM region ${ }^{44}$ This approach is usually referred to as classical or mechanical embedding. Originally in ONIOM, the QM region and MM region interact via mechanical embedding. ${ }^{46}$ Using the ONIOM method, the geometry of the complex (the 3 DPEG molecules bound to the metal ion form a metal-ligands complex), and isolated metal ion and isolated DPEG were optimized. The vibrational frequencies and binding energies of the transition metal and associated ligands were then calculated.

\section{Results and discussion}

When the catechol reacts with the transition metal ions, it is oxidized into a quinone. Three quinones establish six covalent bonds with the central metal ion. Figure 1 shows the optimized structure of this (quinone) $)_{3}-\mathrm{Fe}^{3+}$ complex $\left(\mathrm{Cat} \mathrm{Fe}^{3+}\right)$. Carbon and oxygen atoms are indexed to define various bond lengths and angles. The $\mathrm{O}_{1}-\mathrm{C}_{1}$ and

$\mathrm{O}_{1}$-Fe bond lengths are denoted by $d_{1}, d_{1}^{\prime}$ while $d_{2} d_{2}^{\prime}$ and represent the $\mathrm{O}_{2}-\mathrm{C}_{2}$ and $\mathrm{O}_{2}-\mathrm{Fe}$ bond lengths, respectively. Pertinent bond angles are defined in the Figure 1. The octahedral angle of this structure is on average $92.9^{\circ}$. Three oxidized DOPA molecules crosslinked with one metal ion are shown in Figure 1b. The optimized bond lengths and bond angles of DOPA PEG Fe ${ }^{3+}$ and $\mathrm{Cat} \mathrm{Fe}^{3+}$ are listed in Table 1. The oxidized catechol and DOPA PEG bind strongly to the metal ion, causing a significant change in the bond lengths and bond angles. The binding (cross-link) energies of the complex using four distinct transition metal ions are given in Table 2. The binding energies between the transition metal and the ligands were calculated using equation:

$$
\Delta E=-\left(E_{\text {complex }}-E_{\text {metal }}-3 E_{D P E G}\right)
$$

Where, $E_{\text {complex }}, E_{\text {metal }}$ and $E_{D P E G}$ represent the energies of the metal-ligands complex, the metal ion, and the DOPA-modified PEG (DPEG). All these energies are calculated by optimizing the geometries of the complex and the ligands. Therefore, $\Delta E$ it the energy required to disassemble the complex into an isolated metal atom and three individual ligands.

The binding energy calculated according to Equation 1 shows that DOPA modified PEG polymer $\mathrm{Fe}^{3+}$ cross linked more strongly compared to the other three transition metals $\left(\mathrm{Fe}^{2+}, \mathrm{Cr}^{3+}\right.$ and $\left.\mathrm{Mn}^{3+}\right){ }^{48,49}$ This demonstrates the strong adhesive force between PEG and the $\mathrm{Fe}^{3+}$ ion which is attributed to the extra ability of Fe (III) to oxidize the catcholic groups of DOPA and induce a strong covalent linkage. These values can be compared to the experimental data obtained from the DOPA modified PEG in terms of the penetration force $e^{14,48,50}$ and the Raman spectrum calculation of highly crosslinked adhesive materials. ${ }^{14,18,48,50}$ Experimentally, the strength of cross linking is estimated by the force exerted by the Instron 5544 Materials Testing machine onto the sample to measure the resistive force monitored by a $5 \mathrm{~N}$ load cell during penetration against the rod. It is observed that extensively cross-linked samples produce higher resistive forces 
against rods that are lowered at constant velocity. In computational linking, thus samples with higher binding energy will have stronger studies, the binding energy determines the strength of the cross- cross-linking. ${ }^{15,16}$

Table I Optimized parameters of dopaPEGFe ${ }^{3+}$ and catecholFe ${ }^{3+}$

\begin{tabular}{|c|c|c|c|c|c|c|c|c|c|c|c|c|c|c|}
\hline & $d_{1}(\mathbf{A})$ & $d_{1}{ }_{1}(\mathbf{A})$ & $d_{2}(A)$ & $d_{2}(A)$ & $\theta_{1}\left({ }^{\circ}\right)$ & $\theta_{2}\left({ }^{\circ}\right)$ & $\theta_{1}^{\prime}\left({ }^{\circ}\right)$ & $\theta_{2}^{\prime}\left({ }^{\circ}\right)$ & $\theta_{3}\left({ }^{\circ}\right)$ & $\theta_{3}^{\prime}\left({ }^{\circ}\right)$ & $\theta_{4}\left({ }^{\circ}\right)$ & $\theta_{4}^{\prime}\left({ }^{\circ}\right)$ & $\theta_{5}\left({ }^{\circ}\right)$ & $\theta_{5}^{\prime}\left({ }^{\circ}\right)$ \\
\hline Isolated ${ }^{\mathrm{a}}$ & 1.364 & 0.977 & 1.377 & 0.968 & 0.968 & 113.4 & 107.1 & 111.3 & & & & & & \\
\hline Isolated & 1.349 & 0.945 & 1.362 & 0.942 & 0.942 & 115.6 & 109.6 & III.4 & & & & & & \\
\hline $\mathrm{DPEGFe}^{3+}$ & 1.303 & 2.129 & 1.308 & 2.101 & 2.101 & 110.9 & 118.6 & 111.5 & & & & & & \\
\hline $\mathrm{CatFe}^{3+}$ & 1.32 & 1.95 & 1.32 & 1.95 & 1.95 & 110.8 & 116.5 & 110.7 & 67.23 & 78.86 & 71.44 & 81.87 & 92.3 & 76.2 \\
\hline
\end{tabular}

The previous calculation by Mian et al.'

Table 2: Resonance raman shifts $\left(\mathrm{cm}^{-1}\right)$ for catechol complexes of non-heme iron proteins and models

\begin{tabular}{|c|c|c|c|c|c|c|c|c|c|c|}
\hline System & A & B & C & D & E & $\mathbf{F}$ & G & $\mathbf{H}$ & $\mathbf{I}$ & J \\
\hline 3DopaPEGFe & 532 & 555 & 634 & 787 & 1179 & 1259 & 1344 & & 1464 & 1567 \\
\hline $\mathrm{Fe}(\mathrm{cat}) 3^{3-}$ & 525 & & 628 & 797 & 1158 & 1274 & 1310 & 1363 & 1465 & 1577 \\
\hline $\mathrm{Fe}(\mathrm{cat}) 3^{3-\mathrm{a}}$ & 533 & & 621 & 800 & 1154 & 1262 & 1322 & & 1487 & 1572 \\
\hline $\mathrm{Fe}(\mathrm{HAD}) \mathrm{cat}^{2-\mathrm{a}}$ & & & 630 & 795 & 1158 & 1258 & 1320 & & 1480 & 1576 \\
\hline $\mathrm{Fe}(\mathrm{NTA}) \mathrm{cat}^{2-\mathrm{a}}$ & 526 & & 630 & 794 & 1158 & 1254 & 1312 & & 1473 & 1573 \\
\hline Mefpl pink ${ }^{a}$ & 531 & 591 & 638 & 815 & 1152 & 1274 & 1326 & 1363 & |49| & 1573 \\
\hline Mefpl purple a & 533 & 594 & 639 & 818 & 1152 & 1274 & 1324 & 1427 & 1490 & 1570 \\
\hline $\mathrm{pH} \sim 12^{\mathrm{b}}$ & 529 & 584 & 634 & & & 1270 & 1324 & 1422 & 1484 & \\
\hline Mussel cuticle ${ }^{b}$ & 550 & 596 & 637 & & & 1270 & 1322 & 1422 & 1476 & \\
\hline Mefpl b & 531 & 591 & 638 & & & 1274 & 1326 & 1426 & $|49|$ & \\
\hline
\end{tabular}

a. Reference ${ }^{26}$

b. Reference ${ }^{47}$

Results from the current study are on the top 2 lines and in bold type.

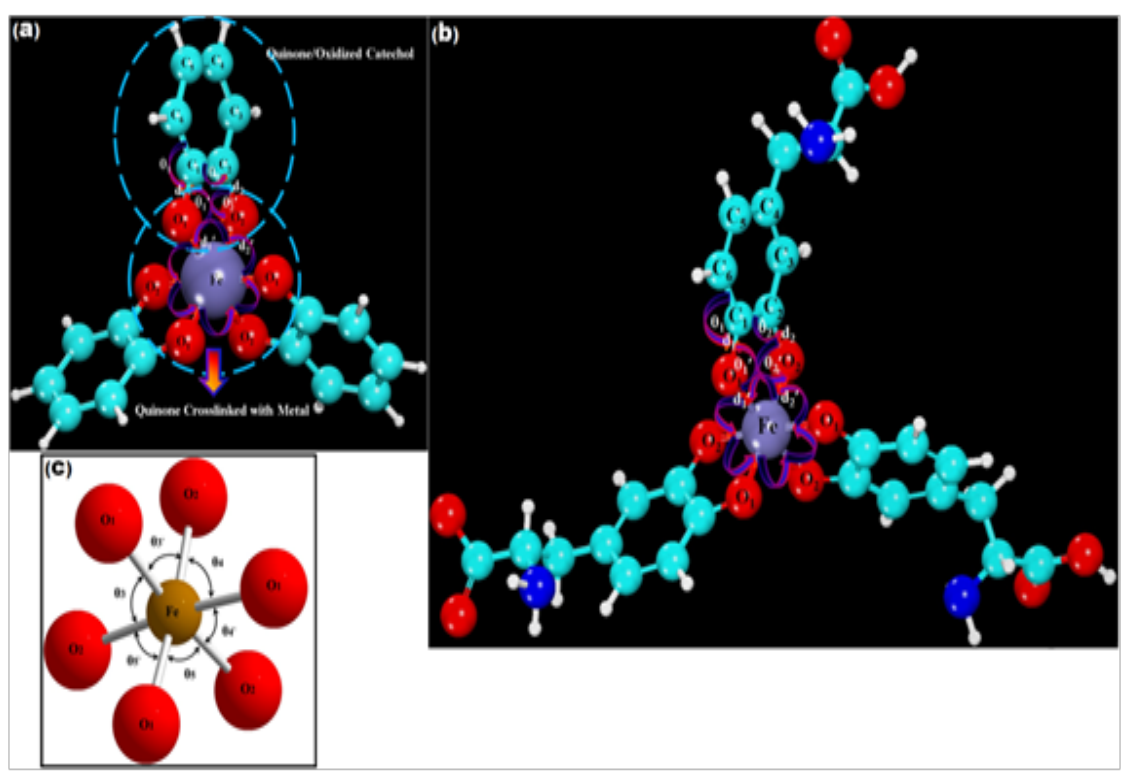

\section{Figure I}

a. Optimized geometry of (quinone) ${ }_{3}-\mathrm{Fe}^{+3}$ complex. Carbon and oxygen atoms are indexed to define bond lengths and angles including $\theta_{1}, \theta_{1}^{\prime}, \theta_{2}$, and $\theta_{2}^{\prime}$

b. Optimized geometry of (oxidized DOPA) ${ }_{3}-\mathrm{Fe}^{+3}$ complex

c. For the tris structure, there are six angles around the Fe metal ion labeled $\theta_{3}, \theta^{\prime}{ }_{3}, \theta_{4}, \theta_{4}^{\prime}, \theta_{5}$ and $\theta^{\prime}{ }_{5}$. 
We will now consider DOPA molecule complexes. The oxidized catechol part of the DOPA molecule, the quinone captures the transition metal ions $\mathrm{Fe}^{2+}, \mathrm{Fe}^{3+}, \mathrm{Cr}^{3+}$ and $\mathrm{Mn}^{3+}$, forming a cross-linked structure as shown in (Figure 2). It is the central part of the complex protein i.e. DOPA PEG molecule. The four different transition metal ions crosslinked with quinone. The binding energies of quinonemetal complexes are shown in Figure 3. In terms of binding energy, $\mathrm{Fe}^{3+}$ shows the highest degree of binding energy $\left(471.7 \mathrm{kcal} \mathrm{mol}^{-1}\right)$ as compared to the other transition metal ions. This is also confirmed by several studies where they found that $\mathrm{Fe}^{3+}$ metal ions is responsible for highly cross linked adhesive materials. ${ }^{15,16,19}$ The optimized geometry of the DOPA PEG Fe ${ }^{3+}$ complex molecule is shown in (Figure 4).

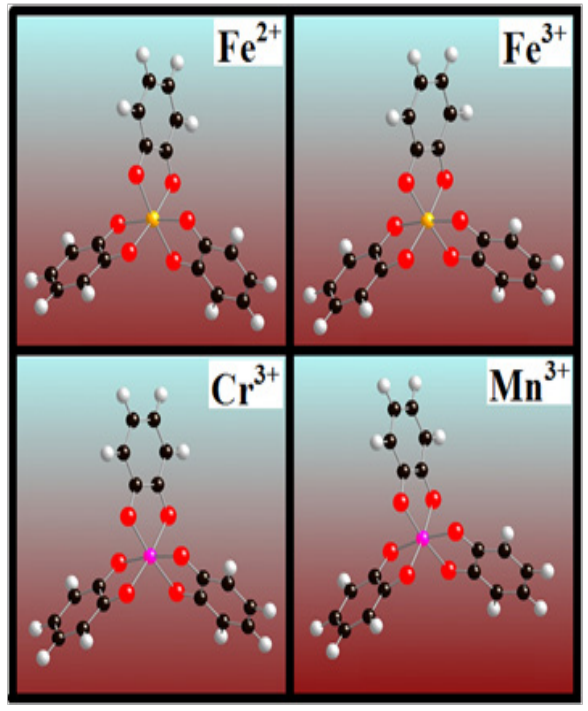

Figure 2 Optimized structures of quinone cross-linked with transition metals $\mathrm{Fe}^{2+}, \mathrm{Fe}^{3+}, \mathrm{Cr}^{3+}$ and $\mathrm{Mn}^{3+}$.

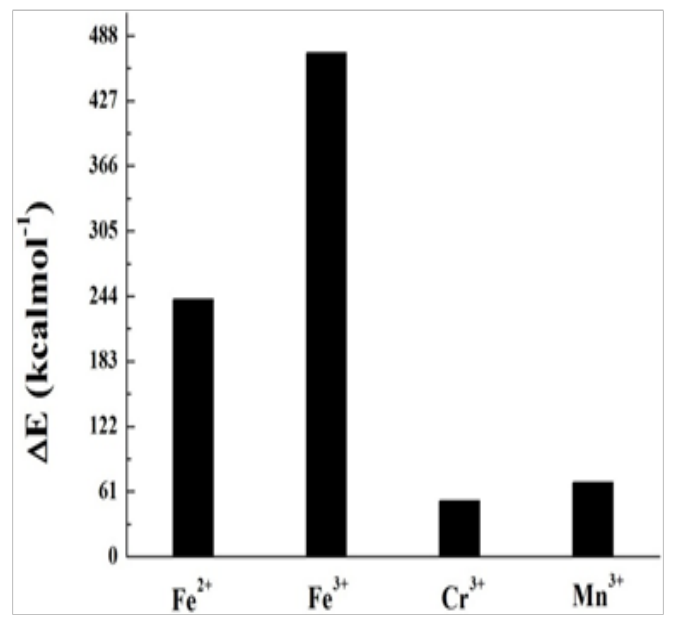

Figure 3 Binding Energy plot for transition metal $\mathrm{Fe}^{2+}, \mathrm{Fe}^{3+}, \mathrm{Cr}^{3+}, \mathrm{Mn}^{3+}$ complexes cross-linked with DOPA modified PEG polymer.

The tris- $\mathrm{Fe}^{3+}$ optimized geometry of the DOPA polyethylene glycol is shown in (Figure 5 \& 6) shows the Raman spectra of oxidized catechol and DOPA modified PEG cross-linked with $\mathrm{Fe}^{3+}$. Vibrational frequencies are scaled to eliminate known symmetric errors in calculated frequency. Raw frequencies values computed at the B3LYP/6-311G** are scaled by a factor of 0.9682 which reduce the systematic errors in frequencies due to over estimation. Use of this factor has been demonstrated to produce very good agreement with experiment for a wide range of systems. ${ }^{49}$ The intensities are an approximation. However, the relative values of the intensities and the actual frequencies may be reliably compared. The Lorentzian line broadening is $11.3 \mathrm{~cm}^{-1}$. For the DOPA functionalized PEG complex polymer $\mathrm{Fe}^{3+}$, where most of the peaks are attributed to the resonance interaction of iron with the catechol moiety of DOPA (Figure 6).

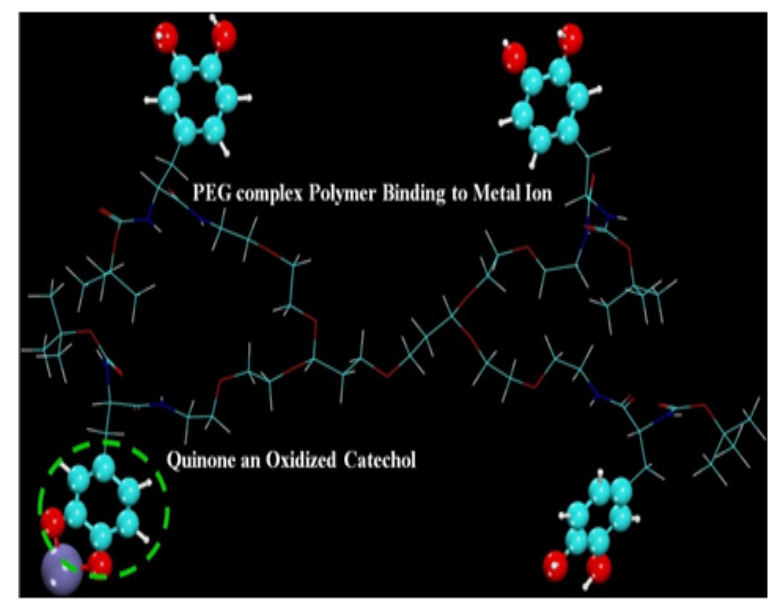

Figure 4 Optimized structure of DOPA modified complex polymer polyethylene glycol (PEG).

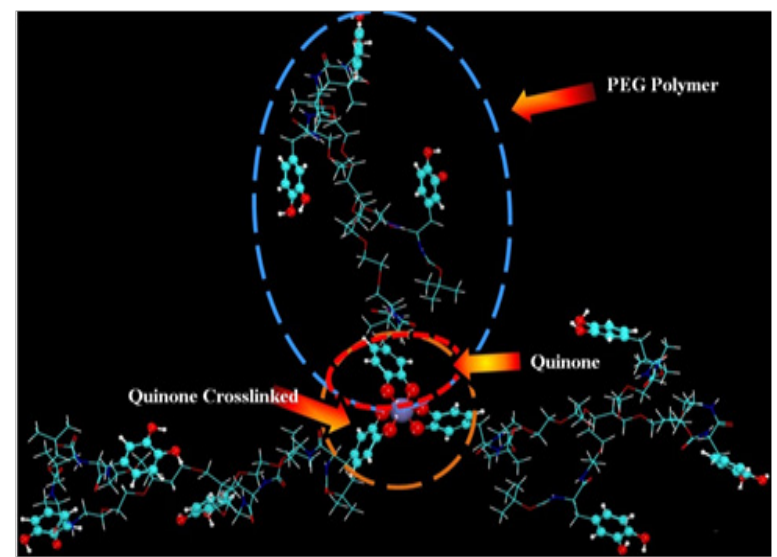

Figure 5 Structure of three DOPA modified complex polymer polyethylene glycol (PEG) molecules cross-linked with one of four different transition metals, $\mathrm{Fe}^{2+}, \mathrm{Fe}^{3+}, \mathrm{Cr}^{3+}$ or $\mathrm{Mn}^{3}$.

The scaled vibrational frequencies give the Raman spectrum of DOPA modified PEG complex polymer which can be compared to the $3 \mathrm{catFe}^{3+}$ complex, iron-catechol and Mefp $1^{26,28,34}$ presented in Table 2. Bidentate iron catecholate complexes have a feature at approximately $530 \mathrm{~cm}^{-1}$ that arises from an iron-catecholate ring mode. We can compare our results to the experimental results of Holten-Andersen ${ }^{34}$ and Harrington et al. ${ }^{34}$ These groups studied $\mathrm{pH}$ induced metalligand cross-linking, and the spectra of Mytilus californianus and M. galloprovincialis thread cuticles, respectively. The Raman spectrum in the range $450-670 \mathrm{~cm}^{-1}$ originates from the chelation of the $\mathrm{Fe}^{3+}$ ion by the oxygen atoms of the catechol. The peaks at approximately 555 and $640 \mathrm{~cm}^{-1}$ are assigned to the vibrations in the bonds between the $\mathrm{Fe}^{3+}$ and the catecholate $\mathrm{C} 3$ and $\mathrm{C} 4$ oxygen's of the catechol respectively, while the peak around $532 \mathrm{~cm}^{-1}$ is assigned to charge transfer interactions of the bidentate chelation. ${ }^{47,34}$ Peaks between 1250 and 1500 are assigned to catechol ring vibrations. ${ }^{34}$ We note that the blue 
line in Figure 6 (DOPA modified PEG) has a big peak at 700 which is not in the experimental data. We do see good matches at 620 and 800 and the 1300 region and the 1460 region. For $\mathrm{Fe}(\mathrm{cat})_{3}{ }^{3-}$, we see fewer peaks, which focus on the Fe-Cat interaction. This allows us to see the difference between PEG and Fe-Cat. In Table 2, we see that the current results for $\mathrm{Fe}$ (cat) ${ }_{3}^{3-}$ compare very closely with the previous work on the line below. In summary, the vibrational frequencies of the Raman spectra are in good agreement with the reference data presented in Table 2. These results along with the binding energy data clearly demonstrate that $\mathrm{Fe}^{3+}$ strongly cross links compared to the $\mathrm{Fe}^{2+}, \mathrm{Cr}^{3+}$ and $\mathrm{Mn}^{3+}$ complex structures. This observation is consistent with the reference data available in the literature. . $^{15,16,26,28}$

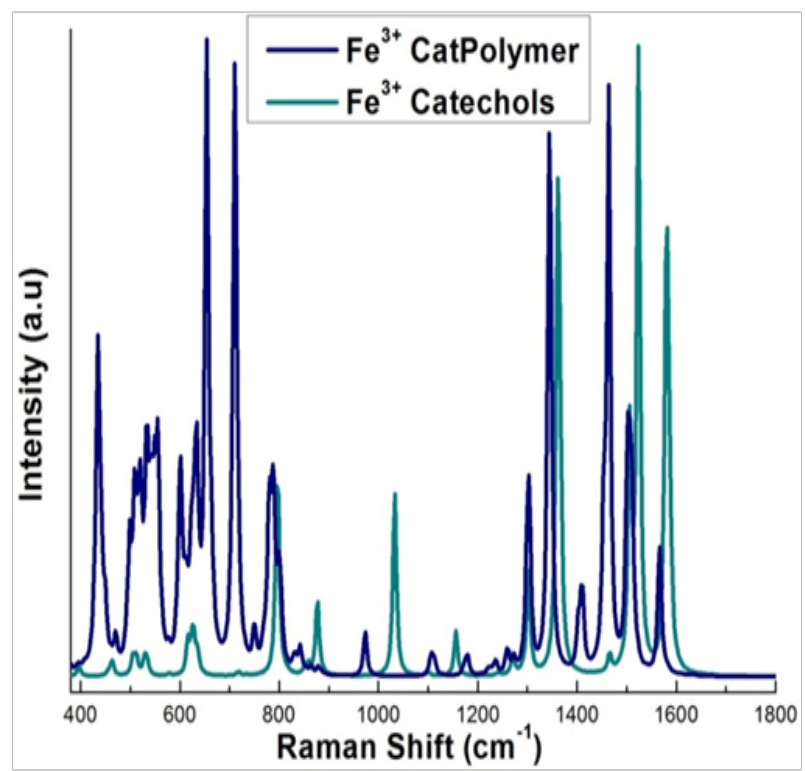

Figure 6 Raman spectrum of $\mathrm{Fe}^{3+}$ cross-linked with three catechols (green), and $\mathrm{Fe}^{3+}$ cross-linked with three DOPA functionalized PEG complex polymers (blue).

\section{Conclusion}

The cross linking of the mussel proteins by transition metals has been studied using the QM/MM method. Complexes of four different transition metal ions $\mathrm{Fe}^{2+}, \mathrm{Fe}^{3+}, \mathrm{Cr}^{3+}$ and $\mathrm{Mn}^{3+}$ with DOPA modified PEG polymers and with quinones were studied. Experimentally, some ions induce curing and the others do not during metal ion cross linking. The role of DOPA is important in curing and is essential not only to stabilize the mussel adhesive, but also for the chelation of metal ions which are readily susceptible to oxidation. The DOPA modified PEG cross linked strongly with $\mathrm{Fe}^{2+}, \mathrm{Fe}^{3+}, \mathrm{Cr}^{3+}$ and $\mathrm{Mn}^{3+}$ ions. Our results reveal that the calculated binding energies of tris- $\mathrm{Fe}^{3+}$ and tris- $\mathrm{Fe}^{2+}$ are higher than tris- $\mathrm{Cr}^{3+}$ and tris- $\mathrm{Mn}^{3+}$. The binding energy for tris- $\mathrm{Fe}^{3+}$ is the highest, while tris- $\mathrm{Cr}^{3+}$ is the lowest. Spectroscopic data indicates that chelation of metal ions brought together multiple protein strands by formation of metal-DOPA complexes 10 . We conclude that tris$\mathrm{Fe}^{3+}$ are primarily responsible for cross linking in marine mussels. The results presented here show that among the metals actively seized by marine mussels, $\mathrm{Fe}^{3+}$ and $\mathrm{Fe}^{2+}$ appear to be the key for curing. The optimal reagents for cross-linking are oxidizing metal ions. This interactive combination of both chelation and oxidation may explain why mussels concentrate iron in their adhesive plaques.

\section{Acknowledgements}

None.

\section{Conflict of interest}

There is no conflict of interest.

\section{References}

1. Mian SA, Yang LM, Saha LC, et al. Fundamental Understanding of Catechol and Water Adsorption on a Hydrophilic Silica Surface:Exploring the Underwater Adhesion Mechanism of Mussels on an Atomic Scale. Langmuir. 2014;30(23):6906-6914.

2. Deming TJ. Mussel byssus and biomolecular materials. Curr Opin Chem Biol. 1999;3(1):100-105.

3. Jo HS, Sohn SJ. Biomimetic Adhesive Materials Containing Cyanoacryl Group for Medical Application. Molecules. 2014;9(10):16779-16793.

4. Mehdizadeh MR, Weng H, Gyawali D, et al. Injectable citrate-based mussel-inspired tissue bioadhesives with high wet strength for sutureless wound closure. Biomaterials. 2012;33(32):7972-7983.

5. Xie D, Guo J, Mehdizadeh MR, et al. Development of injectable citrate-based bioadhesive bone implants. J Mater Chem B. 2015; 3(3):387-398.

6. Jeon EY, Hwang BH, Yang YJ, et al. Rapidly light-activated surgical protein glue inspired by mussel adhesion and insect structural crosslinking. Biomaterials. 2015;67:11-19.

7. Peppas NA, Bures P, Leobandung W, et al. Hydrogels in pharmaceutical formulations. Eur J Pharm Biopharm. 2000;50(1):27-46.

8. Frost SJ, Mawad D, Hook J, et al. Micro-and Nanostructured Biomaterials for Sutureless Tissue Repair. Adv Healthc Mater. 2016;5(4):401-414.

9. Bobba RK, Holly JS, Loy T, et al. Scar Carcinoma of the Lung: A Historical Perspective. Clin Lung Cancer. 2011;12(3):148-154.

10. Horton CE, Crawford HH, Love HG, et al. The Malignant Potential of Burn Scar. Plast Reconstr Surg. 1958;22(4):348-353.

11. Chow A, Marshall H, Zacharakis E, et al. Use of Tissue Glue for Surgical Incision Closure: A Systematic Review and Meta-Analysis of Randomized Controlled Trials. J Am Coll Surgeons. 2010;211(1):114-125.

12. Traver MA, Assimos DG. New generation tissue sealants and hemostatic agents: innovative urologic applications. Rev Urol. 2006;8(3):104-111.

13. Jaime TW, Mark JN, Mary JS, et al. EPR Investigation and Spectral Simulations of Iron-Catecholate Complexes and Iron-Peptide Models of Marine Adhesive Cross-Links. Inorg Chem . 2006;45(19):7736-7747.

14. Taylor SW, Waite JH, Mark M Ross, et al. Trans-2,3-cis-3,4-Dihydroxyprolinea, New Naturally Occurring Amino Acid, Is the Sixth Residue in the Tandemly Repeated Consensus Decapeptides of an Adhesive Protein from Mytilus edulis. J Am Chem Soc. 1994;116(23):10803-10804.

15. Monahan J, Wilker JJ. Specificity of metal ion cross-linking in marine mussel adhesives. Chem Commun. 2003;(14):1672-1673.

16. Monahan, J, Wilker JJ. Cross-Linking the Protein Precursor of Marine Mussel Adhesives: Bulk Measurements and Reagents for Curing. Langmuir. 2004;20(9):3724 -3729.

17. Sever MJ1, Weisser JT, Monahan J, et al. Metal-Mediated Cross-Linking in the Generation of a Marine-Mussel Adhesive. Angew Chem Int Ed Engl. 2004;43(4):448-450.

18. Avdeef A, Sofen SR, Bregante TL, et al. Coordination Chemistry of Microbial Iron Transport Compounds. 9.' Stability Constants for Catechol Models of Enterobactin. J Am Chem Soc. 1978;100(17):5362-5370. 
19. Platz DR, Much DD, Bergheim AL, et al. Composite Article from Engineering Thermoplastics and Polyurethance Elastomer.US 6497782 B1, USA; 2002. p. 1-12.

20. Brubaker CE, Messersmith PB. Enzymatically Degradable Mussel-InspiredAdhesive Hydrogel. Biomacromolecules. 2011;12(12):4326-4334.

21. Fullenkamp DE, Rivera JG, Gong YK, et al. Mussel-inspired silver-releasing antibacterial hydrogels. Biomaterials. 2012;33(15):3783-3791.

22. Brubaker CE, Kissler H, Wang LJ, et al. Biological performance of mussel-inspired adhesive in extrahepatic islet transplantation. Biomaterials. 2010;31(3):420-427.

23. Brubaker CE, Messersmith PB. Enzymatically Degradable Mussel-Inspired Adhesive Hydrogel. Biomacromolecules. 2011;12(12):4326-4334.

24. Barrett DG, Bushnell GG, Messersmith PB. Mechanically Robust, Negative-Swelling, Mussel-Inspired Tissue Adhesives. Adv Healthc Mater. 2013;2(5):745-755.

25. Tangri P, Khurana S, Madhav S. Mucoadhesive Drug Delivery: Mechanism and Methods of Evaluation. Int J Pharm Bio Sci. 2011; 2(1):458-467.

26. Waite JH. Evidence for a Repeating 3,4-Dihydroxyphenylalanine- and Hydroxyproline-containing Decapeptide in the Adhesive Protein of the Mussel, Mytilus edulis L. J Biol Chem. 1983;258(5):2911-2915.

27. M Yu, Hwang J, Deming TJ. Role of L-3, 4-dihydroxyphenylanine in mussel adhesive proteins. J Am Chem Soc. 1999;121(24):5825-5826.

28. Steven WT, D Bruce Chase, Mark HE, et al. Ferric Ion Complexes of a DOPA-Containing Adhesive Protein from Mytilus edulis. Inorg Chem. 1996;35(26):7572-7577.

29. Fan C, Fu J, Zhu W, et al. A mussel-inspired double crosslinked tissue adhesive intended for internal medical use. Acta Biomater. 2016;33:51-63.

30. Fujikawa S, Nakamura S, Koga K. Genipin, a new type of protein crosslinking reagent from Gardenia fruits. $\mathrm{Agr}$ Biol Chem. 1988;52(3):869-870.

31. Olivieri MP, Baier RE, Loomis RE. Surface properties of mussel adhesive protein component films. Biomaterials. 1992;13(14):1000-1008.

32. Bakowies D, Thiel W. Hybrid Models for Combined Quantum Mechanical and Molecular Mechanical Approaches. J Phys Chem. 1996;100(25):10580-10594.

33. Frisch MJ, Trucks W, Schlegel HB, et al. Gaussian 09, Revision A.1. USA: Gaussian Inc; 2009.

34. Harrington MJ, Masic A, Holten-Andersen N, et al. Iron-Clad Fibers: A Metal-Based Biological Strategy for Hard Flexible coatings. Science. 2010;328:216-220.

35. Vreven T, Byun KS, Komaromi I, et al. Combining Quantum Mechanics Methods with Molecular Mechanics Methods in ONIOM. J Chem Theory Comput. 2006;2(3):815-826.

36. Warshel A, Levitt M. Theoretical Studies of Enzymic Reactions: Dielectric, Electrostatic and Steric Stabilization of Reaction of Lysozyme. $J$ Mol Biol. 1976;103(2):227-249.
37. Maseras F, Morokuma K. IMOMM: A New Integrated Ab Initio Molecular Mechanics Geometry Optimization Scheme of Equilibrium Structures and Transition States. J Comput Chem. 1995;16(9):1170-1179.

38. Field MJ, Bash PA, Karplus M. Combined Quantum Mechanical and Molecular Mechanical Potential for Molecular Dynamics Simulations. $J$ Comput Chem. 1990;11(6):700-733.

39. Singh UC, Kollman PA. A Combined Ab Initio Quantum Mechanical and Molecular Mechanical Method for Carrying out Simulations on Complex Molecular Systems: Applications to the $\mathrm{CH}_{3} \mathrm{C} 1+\mathrm{C} 1-\mathrm{Ex}-$ change Reaction and Gas Phase Protonation of Polyethers. J Comput Chem. 1986;7:718-730.

40. Svensson M, Humbel S, Froese RDJ, et al. ONIOM: A Multilayered Integrated $\mathrm{MO}+\mathrm{MM}$ Method for Geometry Optimizations and Single Point Energy Predictions. A Test for Diels-Alder Reactions and $\mathrm{Pt}\left(\mathrm{P}(\mathrm{t}-\mathrm{Bu})_{3}\right)_{2}+\mathrm{H}_{2}$ Oxidative Addition. J Phys Chem. 1996;100(50):19357-19363.

41. Vreven T, Mennucci B, Da Silva CO, et al. The ONIOM-PCM method: Combining the hybrid molecular orbital method and the polarizable continuum model for solvation. Application to the geometry and properties of a merocyanine in solution. J Chem Phys. 2001;115(1):62-72.

42. Karadakov PB, Morokuma K. ONIOM as an efficient tool for calculating NMR chemical shielding constants in large molecules. Chem Phys Letts. 2000;317(6):589-596.

43. Rega N, Iyengar SS, Voth GA, et al. Hybrid Ab-Initio/Empirical Molecular Dynamics: Combining the ONIOM Scheme with the Atom-Centered Density Matrix Propagation (ADMP) Approach. J Phys Chem B. 2004;108(13):4210-4220.

44. Reuter N, Dejaegere A, Maigret B, et al. Frontier Bonds in QM/MM Methods: A Comparison of Different Approaches. J Phys Chem A. 2000;104(8):1720-1735.

45. Gao J, Amara P, Alhambra C, et al. A Generalized Hybrid Orbital (GHO) Method for the Treatment of Boundary Atoms in Combined QM/MM Calculations. J Phys Chem A. 1998;102(24):4714-4721.

46. Kipton H, Powell J, Taylor MC. Interactions of iron(II) and iron(III) with gallic acid and its homologues: a potentiometric and spectrophotometric study. Aust J Chem. 1982;35(4):739-756.

47. Holten-Andersen N, Harrington MJ, Birkedal H, et al. $\mathrm{pH}$-induced metal-ligand cross-links inspired by mussel yield self-healing polymer networks with near-covalent elastic moduli. Proc Natl Acad Sci. 2011;108(7):2651-2655.

48. Kest DO. Method of Bonding using Urethance Base Pressure Sensitive Adhesives. US 3879248, USA; 1975. p. 1-13.

49. Thery V, Rinaldi D, Rivail JL, et al. Quantum Mechanical Computations on Very Large Molecular Systems: The Local Self-Consistent Field Method. J Comput Chem. 1994;15(3):269-282.

50. Nicoll RM, Hindle SA, MacKenzie G, et al. Quantum mechanical/ molecular mechanical methods and the study of Kinetic isotop effects: modelling the covalent junction region and application to the enzyme xylose isomerase. Theor Chem Acc. 2000;106(1-2):105-112. 